\title{
Synthesis of cyclic carbonates from epoxides and carbon dioxide using bimetallic aluminium(salen) complexes
}

\author{
Michael North \\ School of Chemistry, Bedson Building, University of Newcastle, Newcastle upon Tyne NE1 7RU, \\ $U K$ \\ E-mail: Michael.north@ncl.ac.uk
}

\begin{abstract}
Over the last six years, highly active catalysts for the synthesis of cyclic carbonates from epoxides and carbon dioxide have been developed. Initial studies showed that bimetallic aluminium(salen) complexes $[\mathrm{Al}(\text { salen })]_{2} \mathrm{O}$ formed active catalysts and kinetic studies allowed the catalytic cycle to be determined. The catalysts could be immobilized on silica, allowing them to be used in a gas phase flow reactor as well as in batch reactors. The compatibility of the catalysts with waste carbon dioxide present in power station flue gas has been investigated and studies to enhance the commercial applicability of the catalysts by reducing the cost of their production carried out.
\end{abstract}

Keywords: Carbon dioxide, epoxide, cyclic carbonate, catalyst, aluminium, salen

\section{Table of Contents}

1. Introduction

2. Catalyst Discovery

3. Reaction Mechanism

4. One-Component and Immobilized Catalysts

5. Use of Waste Carbon Dioxide

6. Catalyst Cost Reduction

7. Conclusions

8. Acknowledgements

9. References

\section{Introduction}

The world currently generates most of its energy by the combustion of fossil fuels (coal, oil and natural gas) and despite efforts to develop alternative, renewable energy sources, fossil fuels are 
likely to remain the predominant energy source for the next 20-40 years. Combustion of fossil fuels inevitably produces carbon dioxide which is released to the atmosphere. This has resulted in atmospheric carbon dioxide levels rising from $280-385$ ppm since the start of the industrial revolution and is now linked to climate change. ${ }^{1}$ The main solution being proposed to allow continued energy generation by combustion of fossil fuels whilst stabilizing global atmospheric carbon dioxide levels is carbon capture and storage (CCS) in which the carbon dioxide is separated, purified, pressurized and transported for long term underground or undersea storage. ${ }^{2}$ However, CCS is a very energy intensive process which has been estimated to require around $30 \%$ of the total energy produced by a power station.

Instead of just dumping the carbon dioxide, it is attractive to consider utilizing it in the large scale production of chemicals (carbon capture and utilization, CCU). ${ }^{3}$ In this way, an unwanted waste product can be turned into a valuable commodity. The relative scales of production of energy and chemicals inevitably means that only a relatively small amount of carbon dioxide could be recycled through CCU, but this could be a very profitable undertaking and could be used to partially offset the costs associated with CCS for the remaining carbon dioxide. Clearly, for $\mathrm{CCU}$ to be effective the energy requirements of the process should be very low (or the process should be linked to renewable energy), otherwise more carbon dioxide will be generated producing the required energy than is utilized in the chemical production. ${ }^{4}$ The thermodynamic stability of carbon dioxide $\left(\Delta \mathrm{H}_{\mathrm{f}}=-394 \mathrm{~kJ} / \mathrm{mol}\right)$ is a significant limitation in this respect, ${ }^{3}$ but there are a number of transformations of carbon dioxide which have been commercialized. Thus, urea is synthesized from ammonia and carbon dioxide. This highly exothermic reaction $\left(\Delta \mathrm{H}_{\mathrm{r}}=\right.$ $-119 \mathrm{~kJ} / \mathrm{mol}$ ) is the largest scale chemical process currently in operation ( $c a 100$ Mtonnes per annum) and utilizes waste carbon dioxide obtained as a byproduct of hydrogen generation from methane. ${ }^{5}$ On a somewhat smaller scale, salicylic acid has been produced from phenol and $\mathrm{CO}_{2}$ $\left(\Delta \mathrm{H}_{\mathrm{r}}=-31 \mathrm{~kJ} / \mathrm{mol}\right)$ since $1890 .{ }^{6}$ Carbon dioxide is frequently used as an additive in conventional carbon monoxide to methanol plants, ${ }^{7}$ but recently Carbon Recycling International opened the first commercial scale plant for the direct reduction of carbon dioxide to methanol using geothermal energy to produce the required hydrogen from sea water. ${ }^{8}$

Another well-known reaction of carbon dioxide is its reaction with epoxides which can be controlled to form either cyclic carbonates ${ }^{9}$ or polycarbonates ${ }^{10}$ (Scheme 1). Polycarbonate production in this way is currently being commercialized in the UK, Germany, USA and South Korea. The synthesis of cyclic carbonates from epoxides and carbon dioxide has been a commercial process since the $1950 \mathrm{~s}^{11}$ and is now operated commercially by many different companies worldwide. The interest in cyclic carbonates is driven by their wide range of chemical and technological applications. ${ }^{12}$ In particular, they are the solvents used in lithium ion batteries $^{13}$ and also make excellent polar aprotic solvents which can be used as replacements for DMF, DMSO, NMP and HMPA etc. ${ }^{12-14}$ 


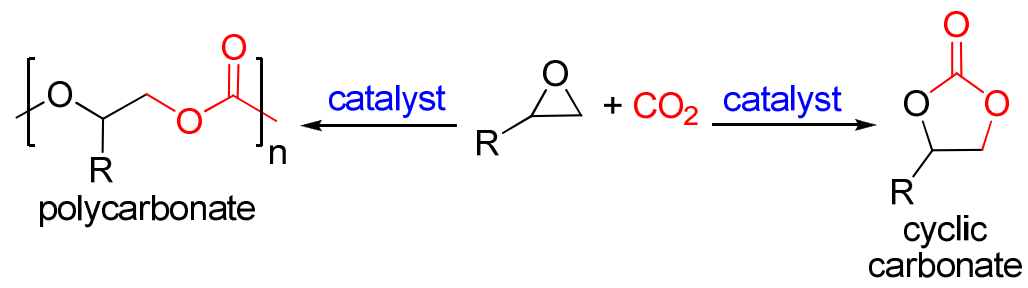

Scheme 1. Synthesis of cyclic carbonates and polycarbonates from epoxides and carbon dioxide.

The synthesis of cyclic carbonates from epoxides and carbon dioxide is a highly exothermic process $\left(\Delta \mathrm{H}_{\mathrm{r}}=-140 \mathrm{~kJ} / \mathrm{mol}\right.$ for ethylene carbonate synthesis (Scheme $\left.1, \mathrm{R}=\mathrm{H}\right)$ ), ${ }^{4}$ yet current commercial processes operate at temperatures above $100{ }^{\circ} \mathrm{C}$ and pressures above 20 bar. As a result, more carbon dioxide is generated producing the required energy than is incorporated into the cyclic carbonate. This account provides an overview of work carried out over the last six years to develop catalysts which are capable of synthesizing cyclic carbonates at ambient temperature and pressure and so which can transform their synthesis from a process which generates carbon dioxide to one which consumes carbon dioxide.

\section{Catalyst Discovery}

A feature of my research over the last 20 years has been the concept that since most chemical reactions involve two reactants, a bimetallic catalyst should be able to activate both components of the reaction and hence be more active than a monometallic catalyst. My group has applied this concept extensively to asymmetric cyanohydrin synthesis and asymmetric enolate alkylation reactions. ${ }^{15}$ In addition, we recognized that the salen ligand (Figure 1) is particularly versatile as it is readily available in both chiral and achiral forms, constructed from modular building blocks, can coordinate to just about any metal, can form complexes with different geometries around the metal, can form polymetallic complexes and gives metal complexes which will catalyze a wide range of transformations. ${ }^{16}$ Therefore, we wondered if a bimetallic metal(salen) complex might form a particularly active catalyst for the synthesis of cyclic carbonates from epoxides and carbon dioxide by pre-activating and pre-organizing both the epoxide and carbon dioxide.

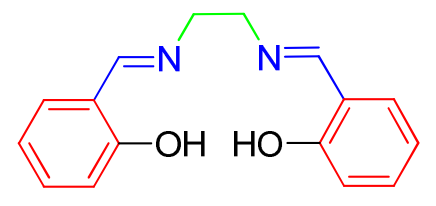

substituents can be introduced:

on the aromatic rings

on the imines

on the ethylene diamine

Figure 1. General structure of a salen ligand.

An initial testing of metal salen complexes revealed that bimetallic aluminium(salen) complexes (optimally $\mathbf{1}$ ) did indeed form particularly active catalysts for the synthesis of cyclic 
carbonates from mono-substituted epoxides and carbon dioxide at ambient temperature and pressure, but only when tetrabutylammonium bromide was used as a cocatalyst (Scheme 2). ${ }^{17}$ Although compound $\mathbf{1}$ appears quite complex, it is available in a single step by treatment of the commercially available salen ligand with aluminium triethoxide followed by an aqueous workup. These early experiments were carried out with wet carbon dioxide obtained by the evaporation of cardice pellets, showing that catalyst 1 would tolerate the presence of moisture. The aliphatic cyclohexyl and tert-butyl groups present in catalyst $\mathbf{1}$ facilitate the solubility of the catalyst in the epoxide, allowing cyclic carbonate synthesis to be carried out under solvent free conditions. Subsequent work ${ }^{18}$ extended the range of cyclic carbonates which could be prepared using catalyst $\mathbf{1}$ and tetrabutylammonium bromide to include the three commercially most important examples (ethylene carbonate, propylene carbonate and glycerol carbonate; Scheme 2, $\mathrm{R}=\mathrm{H}, \mathrm{Me}, \mathrm{CH}_{2} \mathrm{OH}$ respectively). Since ethylene oxide is a gas, the synthesis of ethylene carbonate was carried out in an autoclave at 6 bar carbon dioxide pressure and the synthesis of propylene carbonate was carried out at 1 bar carbon dioxide pressure but at $0{ }^{\circ} \mathrm{C}$ due to the volatility of propylene oxide. All other reactions were carried out at ambient temperature and 1 bar carbon dioxide pressure and epoxides with more than one substituent were not substrates for catalyst 1 and tetrabutylammonium bromide under these reaction conditions. In addition, the structure of complex 1 was unambiguously confirmed by X-ray crystallography and it was shown that complex 1 could be recovered unchanged from the reaction mixture and reused at least 60 times.
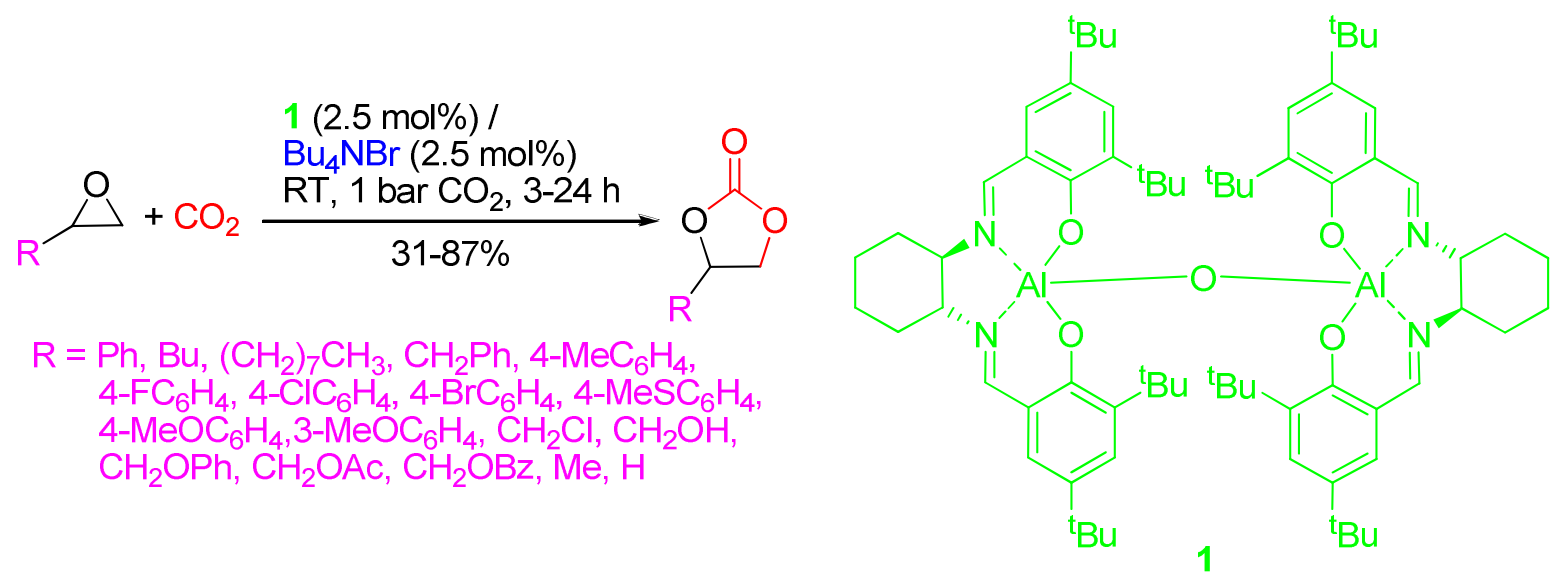

Scheme 2. Synthesis of cyclic carbonates using catalyst 1.

\section{Reaction Mechanism}

The very mild reaction conditions under which complex $\mathbf{1}$ was catalytically active facilitated a detailed analysis of the reaction mechanism using in situ FTIR to study the reaction kinetics. ${ }^{19}$ For this study, it was necessary to use a solvent, but no activity was observed in all conventional 
solvents screened due to the low solubility of carbon dioxide in conventional solvents. However, the substrate screening had shown that propylene oxide was converted into propylene carbonate using catalyst 1 and tetrabutylammonium bromide under solvent free conditions. Towards the end of this reaction, propylene carbonate would be the predominant species present in the reaction. Thus, the catalyst system must be active in the presence of propylene carbonate and we found that it was possible to monitor the kinetics of reactions involving the conversion of styrene oxide into styrene carbonate in propylene carbonate as the solvent. The reaction was found to obey the rate equation:

$$
\text { rate }=\mathrm{k}[\text { epoxide }] \cdot[\mathbf{1}] \cdot\left[\mathrm{CO}_{2}\right] \cdot\left[\mathrm{Bu}_{4} \mathrm{NBr}\right]^{2}
$$

and it was noticed that at low tetrabutylammonium bromide concentrations there was an induction period at the start of the reaction. GC-MS analysis of reaction mixtures showed the presence of tributylamine and kinetics carried out in the presence of added tributylamine confirmed that it had a role in the catalysis. In addition, butyl bromide acted as an inhibitor of the reaction. $^{18}$

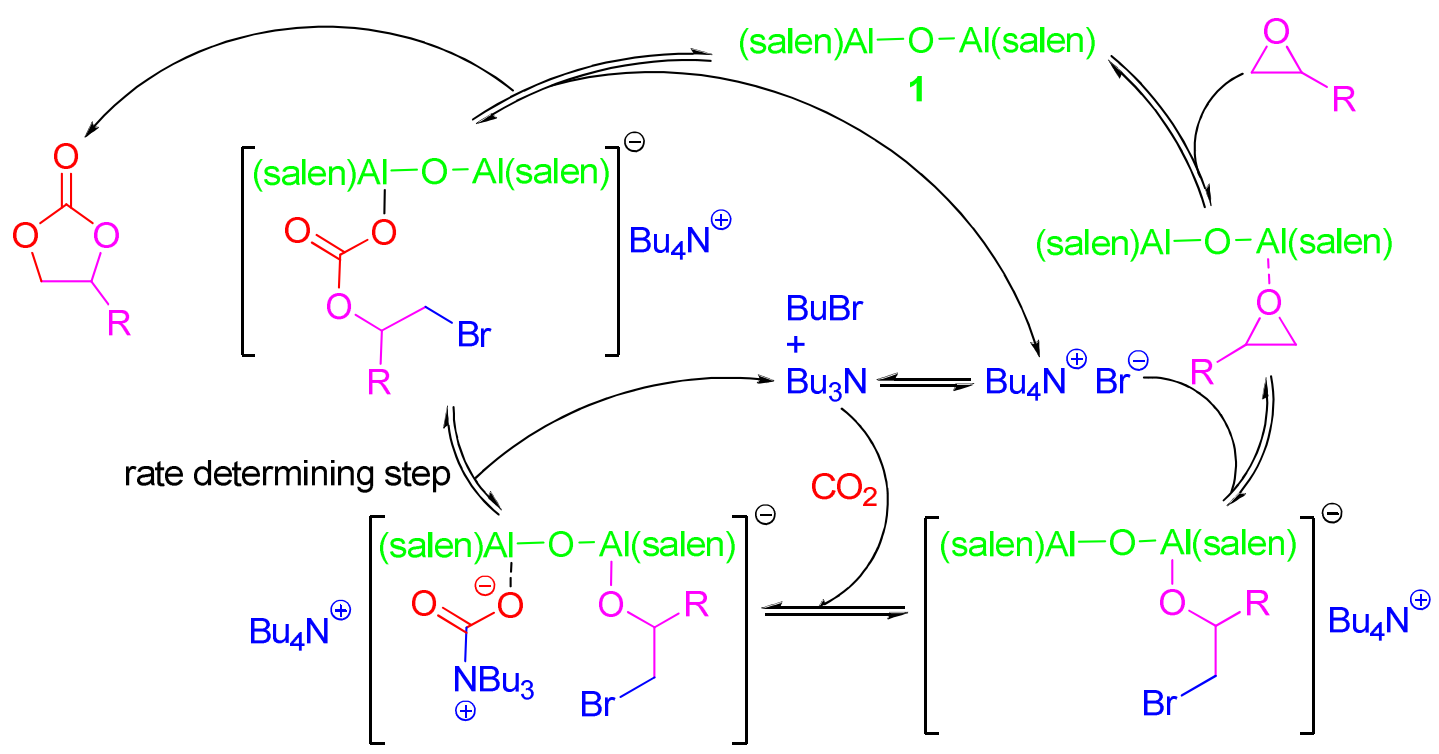

Scheme 3. Catalytic cycle for cyclic carbonate synthesis using catalyst $\mathbf{1}$ and tetrabutylammonium bromide.

The second order dependence of the reaction rate on tetrabutylammonium bromide concentration indicates that two molecules of tetrabutylammonium bromide are involved in the catalytic cycle before or during the rate determining step. One role for the tetrabutylammonium bromide is well established, ${ }^{9}$ it acts as a bromide source to ring-open the epoxide. The induction period is consistent with the second role of tetrabutylammonium bromide being to form tributylamine in situ by a reverse Menschutkin reaction, ${ }^{18}$ and we postulate that the tributylamine reacts with the carbon dioxide to form a carbamate salt. The adduct between a tertiary amine and 
carbon dioxide would normally be very unstable, but the bimetallic aluminium(salen) complex can stabilize both this and the bromo-alkoxide and allow the rate determining carbonate bond formation to occur intramolecularly rather than intermolecularly. Thus, the catalytic cycle shown in Scheme 3 was developed to fully explain all of the reaction features and to account for the exceptionally high catalytic activity associated with catalyst $\mathbf{1}$. The key features of this catalytic cycle have since been shown to be applicable to cyclic carbonate synthesis catalyzed by other catalyst systems as well. ${ }^{20}$

\section{One-component and Immobilized Catalysts}

In view of the high catalytic activity for cyclic carbonate synthesis associated with complex $\mathbf{1}$, we were interested in exploiting catalysts of this structure to develop new technology for the synthesis of cyclic carbonates, namely a gas phase flow reactor in which gaseous epoxide (ethylene or propylene oxide) and carbon dioxide would be passed over an immobilized version of the catalyst to produce liquid cyclic carbonate. Flow reactors offer significant capital and operating cost advantages which become increasingly apparent as the scale of production increases. Thus, a switch from traditional batch production to continuous flow production would reduce the cost of production of cyclic carbonates and open up new markets for their use. However, two problems had to be solved before catalysts related to complex 1 could be used in a gas phase flow reactor. The first of these was the need for an ammonium bromide cocatalyst, since immobilizing two different catalysts that need to interact in the catalytic cycle (Scheme 3) would not be feasible. Secondly, a way had to be found to immobilize the bimetallic aluminium(salen) complex without inhibiting its catalytic activity.

The solution to both of these challenges exploited one of the advantages of the salen ligand, namely that substituents can easily be introduced onto the aromatic rings of the salen ligand. Thus, it was possible to prepare aminomethyl substituted aluminium(salen) complexes 2a-d and then to quaternize the complexes by treatment with benzyl bromide to give one-component catalysts 3a-d (Scheme 4). ${ }^{21}$ Alternatively, reaction of complexes 2a,b with bromomethyl polystyrene gave immobilized complexes $\mathbf{4 a}, \mathbf{b}$ which could be fully quaternized to give supported catalysts $\mathbf{5 a}, \mathbf{b}$. The design of one-component catalysts $\mathbf{3}$ and $\mathbf{5}$ was based on the kinetic data for complex 1 which indicated that at least two quaternary ammonium salts would be required for each bimetallic aluminium(salen) unit. The presence of four ammonium salts symmetrically arranged around complexes $\mathbf{3}$ and $\mathbf{5}$ both satisfied this requirement and simplified the synthesis of the one-component catalysts.

When used in batch reactions at ambient temperature and one bar carbon dioxide pressure under solvent free conditions, one-component catalysts 3a-d all converted styrene oxide into styrene carbonate with the most hydrophobic complex, 3a, giving the best results (89\% yield after a reaction time of 6 hours). Therefore, complex 3a was used to catalyze the conversion of nine other monosubstituted epoxides into the corresponding cyclic carbonates and yields of 51$89 \%$ were obtained after reaction times of 6-24 hours. Polystyrene supported complexes 5a,b 
were only catalytically active in the presence of a solvent which could swell the polystyrene beads. Once again, propylene carbonate was found to be a suitable solvent and both $\mathbf{5 a}$ and $\mathbf{5 b}$ were then found to convert styrene oxide into styrene carbonate at ambient temperature and one bar carbon dioxide pressure. Both polystyrene supported catalysts could be recovered by simple filtration and reused with the yield of styrene carbonate dropping from $79 \%$ to $60 \%$ over four reuses of the catalysts.

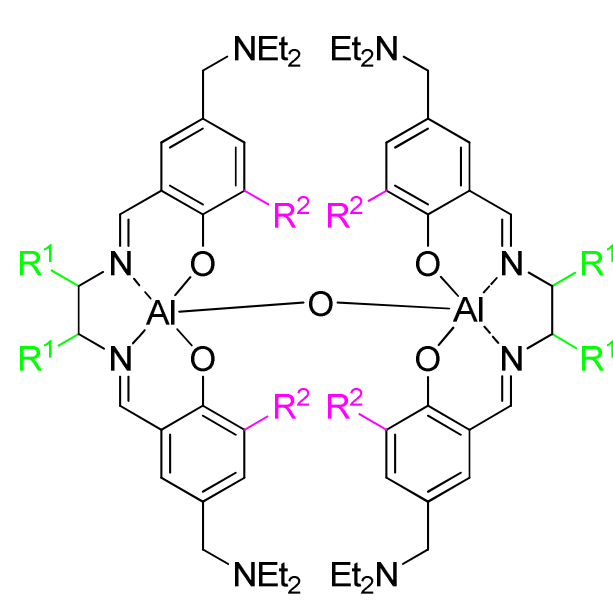

2a-d
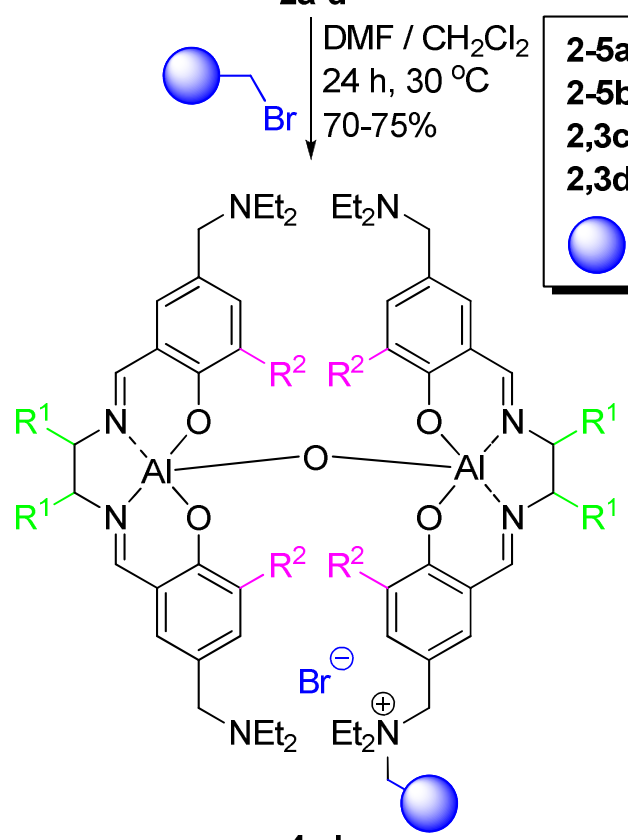

4a,b

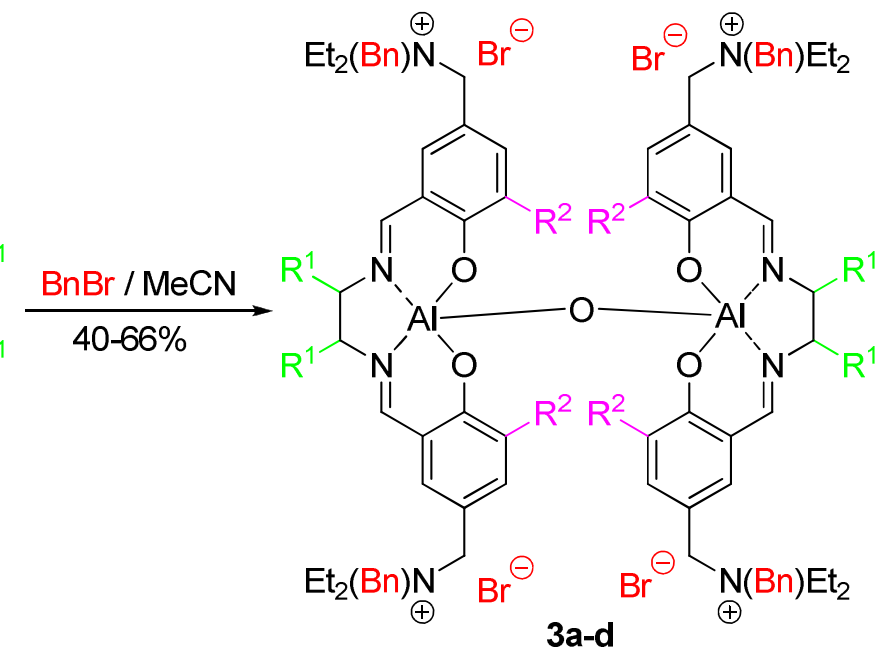

2-5a: $R^{1}-R^{1}=\left(\mathrm{CH}_{2}\right)_{4} ; \mathrm{R}^{2}={ }^{\mathrm{t}} \mathrm{Bu}$

2-5b: $R^{1}=H ; R^{2}={ }^{t} B u$

2,3c: $R^{1}-R^{1}=\left(\mathrm{CH}_{2}\right)_{4} ; \mathrm{R}^{2}=\mathrm{H}$

2,3d: $R^{1}=H ; R^{2}=H$

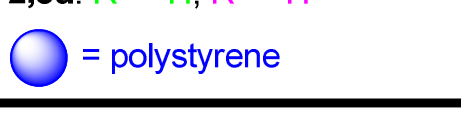

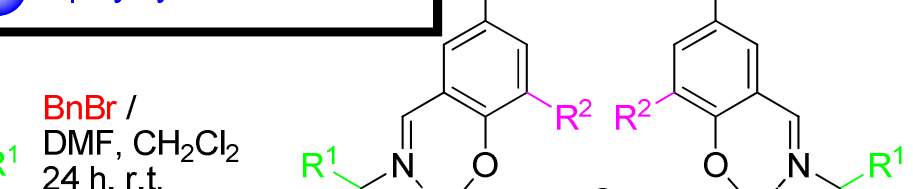
24 h, r.t. $75-83 \%$

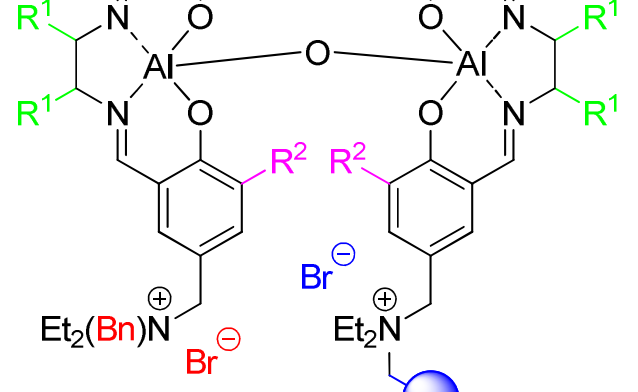

$5 a, b$

Scheme 4. Synthesis of one-component catalysts.

Recently, we reported the synthesis and catalytic activity of the phosphonium salt analogues of complexes 3a-d, and the use of complex $\mathbf{1}$ with phosphonium halide rather than ammonium 
bromide cocatalysts. ${ }^{22}$ In general, the phosphonium salt containing catalysts did catalyze the formation of cyclic carbonates from carbon dioxide and terminal epoxides at ambient temperature and one bar carbon dioxide pressure, but were less active than the corresponding ammonium bromide based systems. Catalysts with bromide counterions displayed higher catalytic activity than those with chloride counterions and the solubility of the catalyst in the epoxide also influenced the catalytic activity. These results provided further evidence for the importance of tertiary amine formation for carbon dioxide activation as required by the mechanism shown in Scheme 3.

Having developed one-component and immobilized catalysts, the remaining challenge was to design and build a gas-phase flow reactor. The most difficult part of this was the gas delivery system since ethylene oxide and propylene oxide both have boiling points below $35{ }^{\circ} \mathrm{C}$ but are supplied as liquids (pressurized in the case of ethylene oxide). Therefore, we developed the flow reactor shown in Figure 2 in which carbon dioxide and nitrogen are used to evaporate the epoxide at a known rate before the mixture of three gases is passed through a column packed with immobilized catalyst and held in a thermostatically controlled oven. ${ }^{23}$ Preliminary experiments showed that polystyrene supported catalysts $\mathbf{5 a}, \mathbf{b}$ were not suitable for use in the flow reactor as they swelled and clogged the reactor. Therefore, amorphous silica (particle size 43-60 $\mu \mathrm{m}$; pore size $60 \AA$ ) supported catalysts $\mathbf{6 a , b}$ (Figure 3) were prepared by the same route shown in Scheme 4. Since catalysts 6 would inevitably be heterogeneous catalysts, the relatively expensive 1,2-diaminocyclohexane unit which was used to enhance the solubility of catalyst $\mathbf{1}$ was discarded in favor of a much less expensive 1,2-diaminoethane unit.

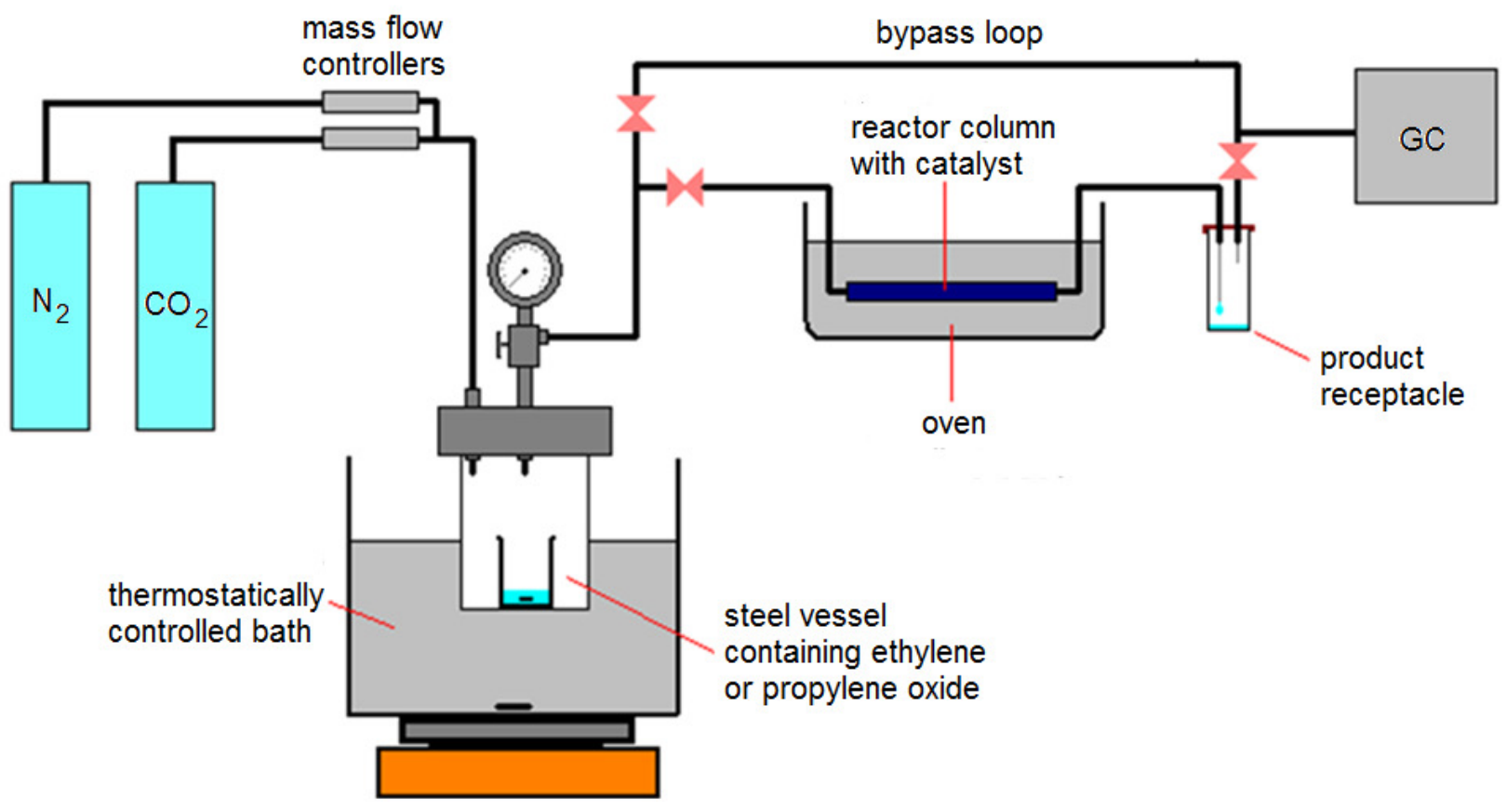

Figure 2. Schematic diagram of the gas-phase flow reactor. 
Catalysts 6a,b were initially tested in batch reactions with styrene oxide as substrate and propylene carbonate as solvent at ambient temperature and one bar carbon dioxide pressure. The amount of catalyst used was standardized at $2.5 \mathrm{~mol} \%$ of active sites (relative to styrene oxide) as determined by ICPOES aluminium analysis. After 20 hours, catalysts $\mathbf{6 a}, \mathbf{b}$ gave conversions of 69 and $78 \%$ respectively. The catalysts could be recovered by simple filtration and reused repeatedly. Figure 4 shows the results obtained during 32 reuses of catalyst $6 \mathbf{a}$ with propylene oxide as substrate under solvent free conditions, the propylene carbonate being simply distilled out of the flask at the end of each reaction. It is apparent from Figure 4 that the activity of catalyst 6a drops off markedly over the first 14 reactions, but that full catalyst activity can be restored by treatment of the silica supported catalyst with benzyl bromide. This trend is consistent with that seen earlier in reuse experiments when catalyst $\mathbf{1}$ and tetrabutylammonium bromide were used as catalyst and is due to a reverse Menschutkin reaction occurring which eventually converts all of the quaternary ammonium salts into the corresponding tertiary amines with the alkyl bromide byproduct being distilled away with the propylene carbonate (Scheme 5). Treatment of the deactivated catalyst with benzyl bromide then requaternizes the amines and restores full catalytic activity. The reverse Menschutkin reaction appears to be selective for the less hindered bonds of the quaternary ammonium salt (bond type 'a' in Scheme 5) as cleavage of bonds of type 'b' or 'c' would result in irreversible catalyst deactivation.

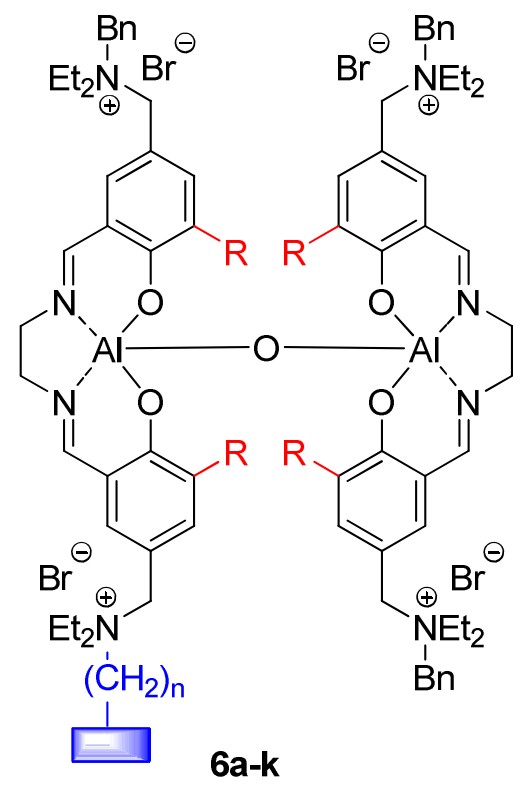

a: $\mathrm{R}={ }^{\mathrm{t}} \mathrm{Bu}, \mathrm{n}=3$, support $=$ amorphous silica (Fluorochem LC301)

b: $R=H, n=3$, support = amorphous silica (Fluorochem LC301)

c: $R={ }^{t} B u, n=3$, support $=$ MCM-41

d: $R={ }^{\mathrm{t}} \mathrm{Bu}, \mathrm{n}=3$, support $=$ solgel

e: $R={ }^{t} B u, n=3$, support = amorphous silica (Davisil 636)

f: $R={ }^{t} B u, n=3$, support $=$ amorphous silica (Davisil 646)

g: $R={ }^{\mathrm{t}} \mathrm{Bu}, \mathrm{n}=3$, support $=$ amorphous silica (Davisil 635)

h: $R={ }^{t} B u, n=3$, support $=$ amorphous silica (Davisil 633)

i: $R={ }^{t} \mathrm{Bu}, \mathrm{n}=3$, support $=$ amorphous silica (Davisil 643)

$\mathrm{j}: \mathrm{R}={ }^{\mathrm{t}} \mathrm{Bu}, \mathrm{n}=3$, support $=$ amorphous silica (Merck 1.15111)

k: $R={ }^{\mathrm{t} B u}, \mathrm{n}=11$, support $=$ amorphous silica (Fluorochem LC301)

Figure 3. Structure of silica supported catalyst. 


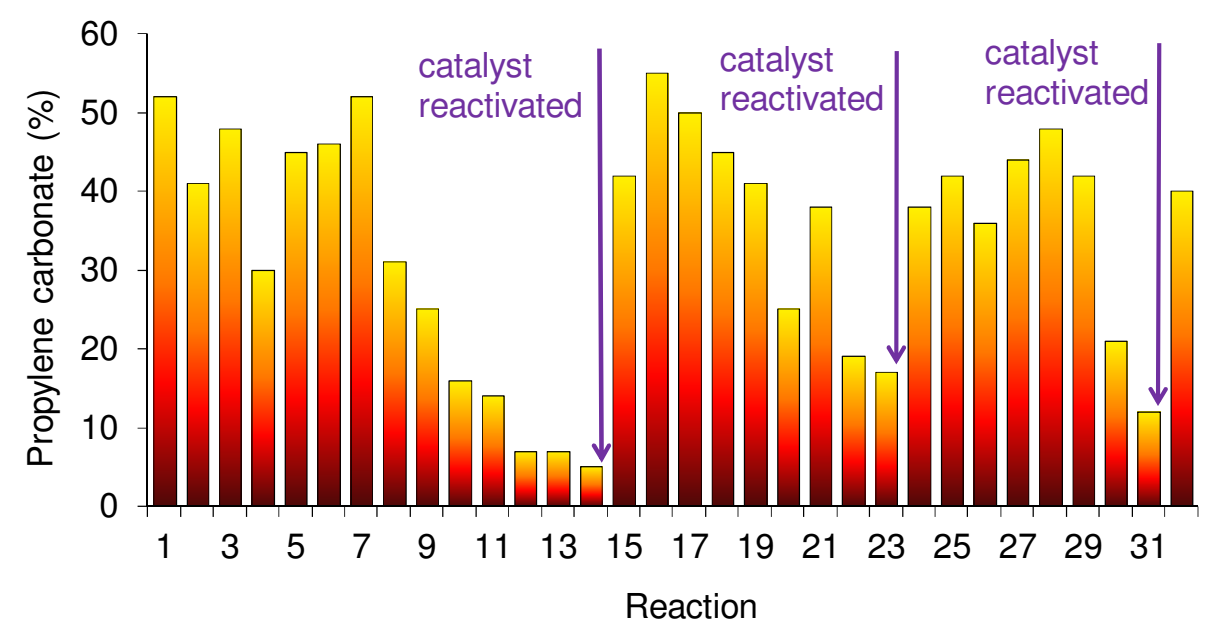

Figure 4. Reuse of catalyst 6a.
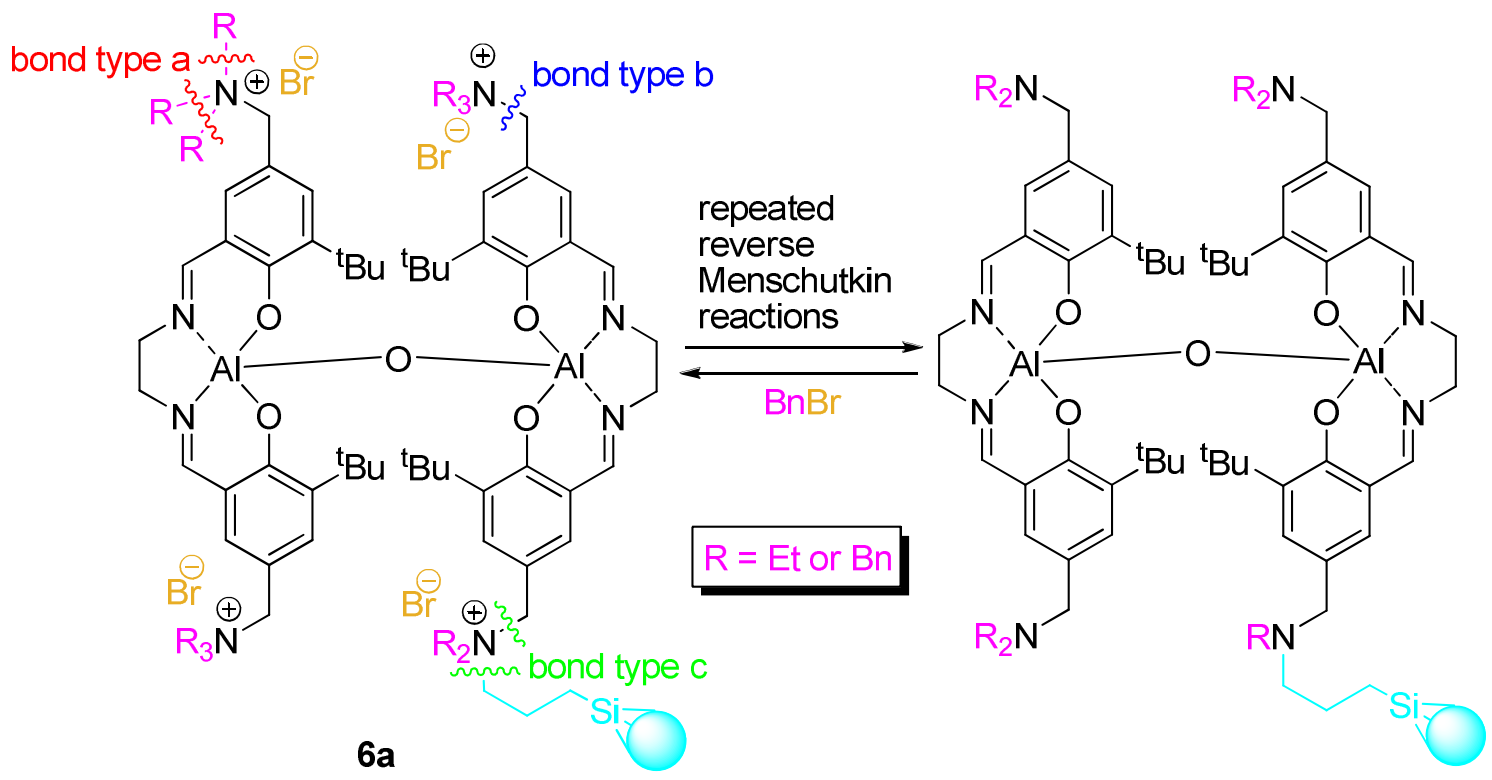

Scheme 5. Deactivation and reactivation of silica supported catalysts.

Catalyst 6a was then used to prepare ethylene or propylene carbonate in the gas-phase flow reactor. Preliminary experiments using a $15 \times 1 \mathrm{~cm}$ column packed with $2.17 \mathrm{~g}$ of silica supported catalyst $6 \mathbf{a}$ and a gas composition of $21 \%$ carbon dioxide, $25 \%$ ethylene oxide and $54 \%$ nitrogen showed that at $20{ }^{\circ} \mathrm{C}$ there was little or no reaction, whilst at $60{ }^{\circ} \mathrm{C} 97 \%$ of the carbon dioxide passing through the column was converted into ethylene carbonate. To increase the turn over frequency $(\mathrm{TOF}=$ moles of product $/($ moles of catalyst active sites $\times$ time) $)$, the column length was reduced to $3 \mathrm{~cm}$ (containing $0.43 \mathrm{~g}$ of catalyst 6a) and the reaction temperature increased to $100{ }^{\circ} \mathrm{C}$. Under these conditions, $14 \%$ of the carbon dioxide was converted into ethylene carbonate, giving a TOF of $1.4 \mathrm{~h}^{-1}$. The flow reactor was then operated 
continuously for seven days to allow catalyst deactivation to be studied. It is apparent from the data in Figure 5, that the catalyst loses half its activity over a period of six days, but that this can be fully restored by requaternization of the catalyst using benzyl bromide (Scheme 5).

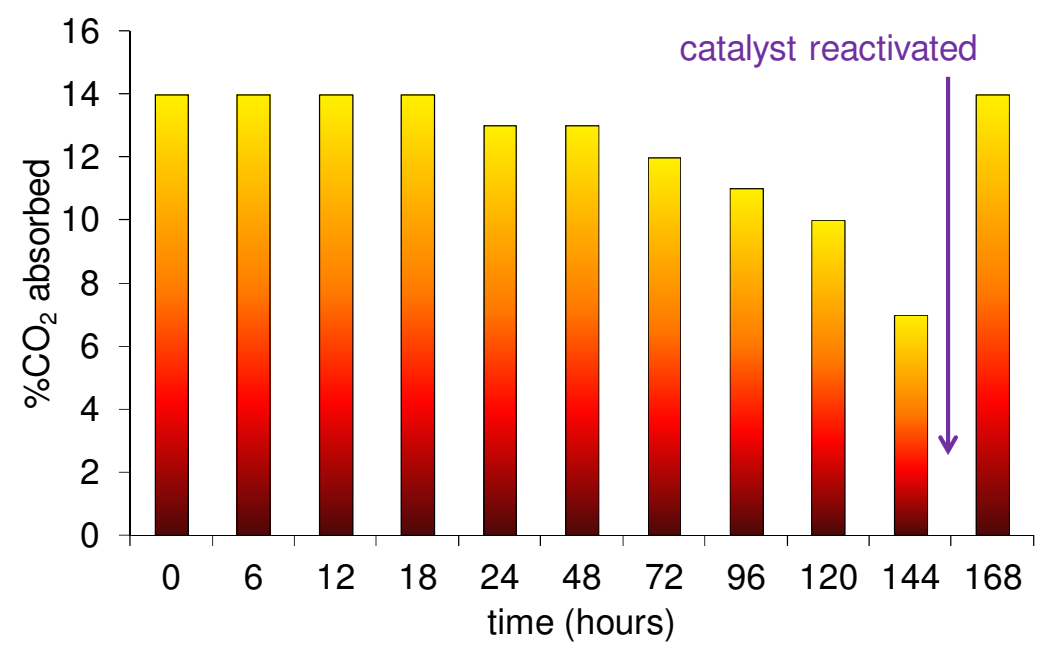

Figure 5. Deactivation of catalyst $6 \mathbf{a}$ in the gas-phase flow reactor.

The nature of the silica support material could have a significant impact on the catalytic activity of silica supported catalysts $\mathbf{6}$, most obviously by affecting the catalyst loading, but also by influencing the accessibility of catalyst sites on the support and how well the reactants interact with the supported catalyst. Therefore a range of different silicas were investigated as support materials and the results are presented in Table 1. Initially the non-amorphous silica MCM-41 6c and a solgel 6d were investigated as supports. Both gave higher TOFs than the amorphous silica $\mathbf{6 a}$, however the increase in catalyst activity was offset by a higher cost of the catalyst support, especially in the case of MCM-41. Subsequently a range of amorphous silicas $\mathbf{6 e - j}$ with differing particle sizes and pore sizes were used as catalyst supports. ${ }^{24}$ The results indicate that pore size had no significant impact on the TOF (compare 6e,f or $\mathbf{6 h}, \mathbf{i}$ ), but as the particle size increased the TOF decreased (compare $\mathbf{6 e}, \mathbf{g}, \mathbf{h}, \mathbf{j}$ ). This can be explained as under the reaction conditions, the ethylene oxide and carbon dioxide are gases, but ethylene carbonate is formed as a liquid which coats the silica particles. Carbon dioxide is known to be soluble in cyclic carbonates and the smaller silica particles give a higher total surface area within the reactor to which the ethylene carbonate can bind. As the ethylene carbonate is formed it will act as a solvent, dissolving both the ethylene oxide and carbon dioxide and concentrating them on the surface of the silica where they can react in the presence of aluminium(salen) units. Each of catalysts 6e-j showed a similar trend in catalyst deactivation / reactivation to that shown in Figure 5 for catalyst $\mathbf{6 a}$ with catalyst deactivation occurring in each case over a period of 6-7 days. 
Table 1. Influence of silica support on TOF of silica supported catalysts ${ }^{\mathrm{a}}$

\begin{tabular}{ccccc}
\hline Catalyst & Silica & Particle size $(\mu \mathrm{m})$ & Pore size $(\AA)$ & TOF \\
\hline $\mathbf{6 a}$ & Fluorochem LC301 & $43-60$ & 60 & 1.38 \\
$\mathbf{6 c}$ & MCM-41 & - & 25 & 21.0 \\
$\mathbf{6 d}$ & solgel & - & - & 5.2 \\
$\mathbf{6 e}$ & Davisil 636 & $250-500$ & 60 & 0.15 \\
$\mathbf{6 f}$ & Davisil 646 & $250-500$ & 150 & 0.12 \\
$\mathbf{6 g}$ & Davisil 635 & $150-250$ & 60 & 0.33 \\
$\mathbf{6 h}$ & Davisil 633 & $38-75$ & 60 & 0.99 \\
$\mathbf{6 i}$ & Davisil 643 & $38-75$ & 150 & 1.22 \\
$\mathbf{6 j}$ & Merck 1.15111 & $15-40$ & 60 & 1.32 \\
$\mathbf{6 k}^{\mathrm{b}}$ & Fluorochem LC301 & $43-60$ & 60 & 0.41 \\
\hline
\end{tabular}

${ }^{\mathrm{a}} \mathrm{All}$ TOFs determined for ethylene carbonate synthesis at $100{ }^{\circ} \mathrm{C}$ except for $\mathbf{6 d}$ where a temperature of 60 ${ }^{\circ} \mathrm{C}$ was used.

${ }^{\mathrm{b}}$ An eleven carbon linker between the silica and ammonium group was used instead of the three carbon linker used in catalysts $\mathbf{6 a - j}$.

Finally, the effect of increasing the length of the linker between the silica and the aluminium(salen) unit was investigated by the synthesis of catalyst $\mathbf{6 k}$ which has an eleven carbon linker rather than the three carbon linker used for catalysts $6 \mathbf{6}-\mathbf{j} .{ }^{24}$ Catalyst $\mathbf{6 k}$ was found to be less active than catalyst $\mathbf{6 a}$, an effect which may be due to the aluminium(salen) units being outside the solvation shell of the silica particles and hence the catalysis not benefiting from the concentration effect of the silica becoming coated with ethylene carbonate. In addition, catalyst 6k was found to deactivate more rapidly than catalyst $\mathbf{6 a}$ and full catalyst activity could not be restored even after treatment with benzyl bromide. This suggests that with the longer linker, cleavage of bonds of type 'c' (Scheme 5) becomes more prevalent, resulting in permanent cleavage of the aluminium(salen) unit from the silica support. This was supported by ICPOES data which showed that after reactivation, catalyst $6 \mathbf{k}$ contained only $75 \%$ of its original aluminium concentration (and its activity could only be restored to $73 \%$ of its original value.

\section{Use of Waste Carbon Dioxide}

It is highly desirable that new technologies developed to utilize carbon dioxide as part of a CCU system are compatible with carbon dioxide at the concentrations, pressures and purities at which it is readily available as waste. In this way all of the costs (financial and energy) associated with purifying, concentrating and pressurizing the waste carbon dioxide can be avoided. Waste carbon dioxide is produced with many different purities, but the largest scale and least pure form is the carbon dioxide present in the flue-gases of a fossil fuel power station which typically has a 
concentration of 6-13\% carbon dioxide and contains numerous other impurities including water vapor, nitrogen oxides and sulfur oxides.
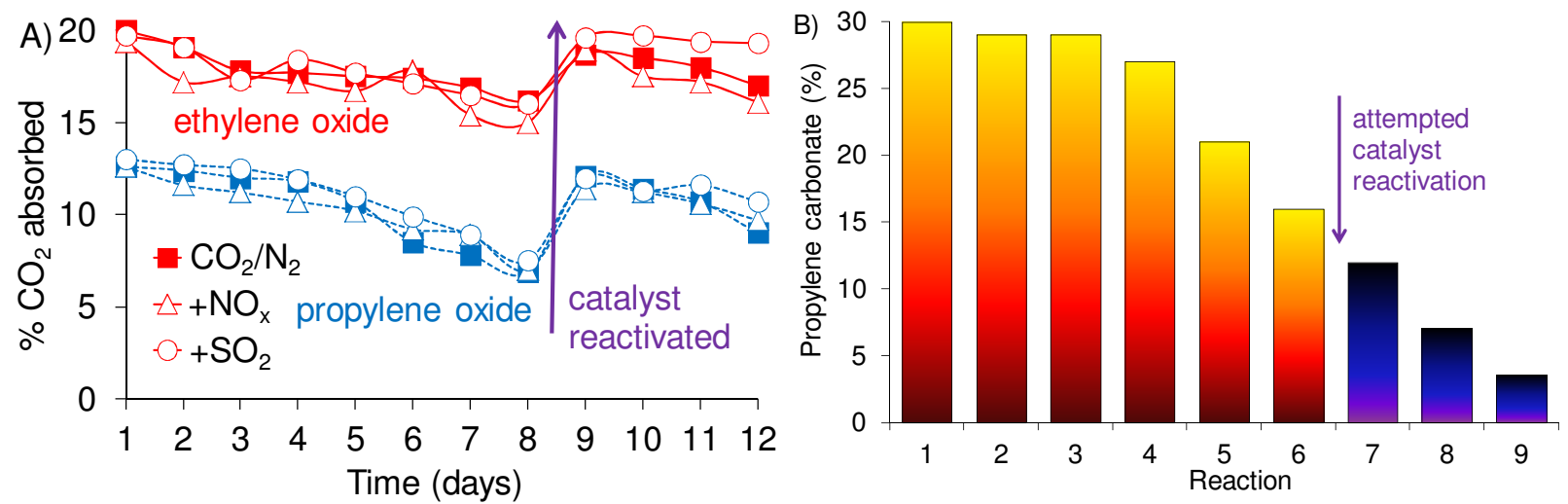

Figure 6. Use of simulated flue-gas with catalyst 6a. A) Continuous flow reactions at $100{ }^{\circ} \mathrm{C}$. Reactions were carried out a flow rate of $4.3 \mathrm{~mL} \mathrm{~min}^{-1}$ with a gas composition of $16 \% \mathrm{CO}_{2}, 18 \%$ propylene or ethylene oxide, $66 \% \mathrm{~N}_{2}$ and impurity concentrations (when present) of $\mathrm{SO}_{2} 1700$ ppm, NO $661 \mathrm{ppm}$ and $\mathrm{NO}_{2} 36 \mathrm{ppm}$. B) Batch reactions showing the effect of sulfur trioxide on catalyst lifetime.

Since flue-gas is not commercially available and cannot be bottled, we investigated the use of simulated flue-gas as a carbon dioxide source for cyclic carbonate synthesis using silica supported catalyst $\mathbf{6 a}$ in the gas-phase flow reactor. ${ }^{25}$ The simulated flue gas was composed of nitrogen doped with carbon dioxide (19.5\%) and either sulfur dioxide (1700 ppm) or a mixture of nitrogen monoxide (661 ppm) and nitrogen dioxide (36 ppm). The concentrations of nitrogen and sulfur oxides were chosen to be 7-20 greater than those present in typical flue-gas in a coal fueled power station. The carbon dioxide concentration was chosen so that after addition of epoxide, the concentration of carbon dioxide in the gas stream entering the flow reactor would be $16 \%$ which is close to the upper limit for carbon dioxide present in flue-gas. Figure 6A shows the effect of 12 days continuous operation of the flow reactor with either pure carbon dioxide in nitrogen or simulated flue-gas using either ethylene oxide or propylene oxide as substrate. It is apparent that the nitrogen and sulfur oxides present in the simulated flue-gas had no detrimental effect on the catalyst activity, lifetime or ability to be reactivated.

Flue-gas also contains sulfur trioxide (20-40 ppm) which is a solid at ambient temperature and pressure. Therefore, its effect on cyclic carbonate synthesis catalyzed by silica supported catalyst 6a was investigated in batch reactions carried out as described earlier (Figure 4), except that sulfur trioxide $(25,000-37,000 \mathrm{ppm})$ was added to each consecutive reaction. The results of this study are shown in Figure 6B. In this case, the catalyst could not be reactivated by treatment with benzyl bromide indicating that it was being irreversibly destroyed by the sulfur trioxide. However, the concentration of sulfur trioxide in each of the reactions represented in Figure 6B is so high that it corresponds to more than three months exposure to sulfur trioxide in real flue gas 
and therefore any loss of catalyst activity due to its reaction with sulfur trioxide would not be apparent for at least one year of real usage.

Since not all components of flue-gas can be readily simulated, the exposure of catalyst $\mathbf{6 a}$ to real flue gas generated by burning coal or natural gas in a commercial power station test facility was also investigated. ${ }^{26}$ For this study, flue gas which had been subjected to electrostatic precipitation to remove particulate matter, but not subjected to any $\mathrm{NO}_{\mathrm{x}}$ or $\mathrm{SO}_{\mathrm{x}}$ removal was allowed to pass through columns packed with catalyst 6a for 4-16 hours. The flue gas exposed catalyst was then analysed by ICPOES to show that there had been no loss of catalyst from the support on exposure to flue-gas and used to catalyse either the synthesis of styrene carbonate from styrene oxide in consecutive batch reactions (Figure 7A) or ethylene carbonate from ethylene oxide in the gas-phase flow reactor (Figure 7B). It is apparent from Figure 7A that there is some loss of catalytic activity when catalyst $\mathbf{6 a}$ is exposed to real flue-gas. However, in the case of flue-gas from combustion of natural gas, this appears to be totally reversible after the first catalyst reactivation. The most likely explanation for this is that the bromide ions present in catalyst 6a which play a role in the catalytic cycle shown in Scheme 3 are replaced by other anions (sulfate, nitrate, etc) on exposure to flue gas. The catalyst reactivation process with benzyl bromide then restores the bromide counterions (see Scheme 5) resulting in the restoration of catalytic activity.
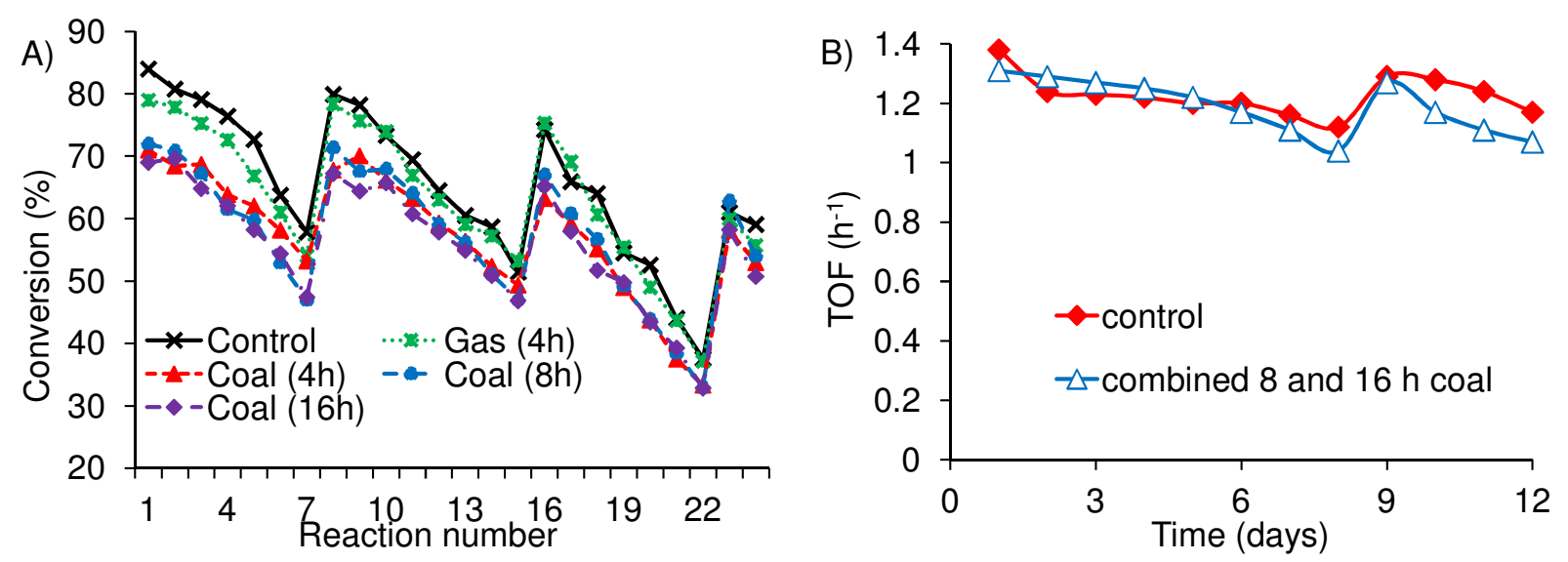

Figure 7. Synthesis of cyclic carbonates using flue-gas exposed catalyst 6a. A) Synthesis of styrene carbonate in batch reactions. The catalyst was reactivated after reactions 7, 15 and 22. B) Synthesis of ethylene carbonate in the flow reactor at $100{ }^{\circ} \mathrm{C}$. The catalyst was reactivated after day eight. The composition of the gases was $\mathrm{CO}_{2} 17 \%$, ethylene oxide $17 \%$ and $\mathrm{N}_{2} 66 \%$ with a total flow rate of $4.2 \mathrm{~mL} \mathrm{~min}^{-1}$ (at $25^{\circ} \mathrm{C}$ ).

Exposure of catalyst $\mathbf{6 a}$ to flue-gas from combustion of coal has a more detrimental effect of catalyst activity in batch reactions. However, Figure 7A shows that the effect does not depend on how long the catalyst was exposed to flue-gas for. Electrostatic precipitation will not remove all of the particulate matter in the flue gas, and the results can be explained by the remaining 
particulate matter blocking the more hindered catalyst sites within silica supported catalyst $6 \mathbf{6}$. However, once these sites are blocked, there is no further detrimental effect of the flue gas. It is also apparent from Figure 7A, that there is a slow loss of intrinsic catalyst activity as each reactivation was less effective than the proceeding one. ICPOES showed that after the first 22 reaction cycles shown in Figure 7A, the catalyst samples had lost around 20\% of their original aluminium content, suggesting that occasionally, bonds of type 'c' (Scheme 5) are cleaved during the reverse Menschutkin reaction resulting in irreversible loss of catalyst from the silica support.

In contrast to the above results, when catalyst $\mathbf{6 a}$ which had been exposed to flue-gas from combustion of coal was used in the gas-phase flow reactor (Figure 2), no decrease in catalyst activity relative to a control sample was apparent (Figure 7B). The flow reactor was operated with a total gas flow rate of $4.2 \mathrm{~mL} \mathrm{~min}^{-1}$ at $25{ }^{\circ} \mathrm{C}$, which corresponds to $5.3 \mathrm{~mL} \mathrm{~min}^{-1}$ at $100{ }^{\circ} \mathrm{C}$, giving a residence time of just eleven seconds. Thus, it may be that only the most exposed catalyst sites are ever catalytically active in the flow reactor, and therefore, blocking access to the more hindered sites has no effect on the catalyst activity.

A number of options are currently being investigated to facilitate CCS. One of these is oxyfuel combustion in which a ceramic membrane is used to separate oxygen from air. Natural gas is then combusted in the pure oxygen, giving a flue gas which comprises only carbon dioxide and water. In collaboration with the group of Metcalfe, we have also shown that catalyst $\mathbf{1}$ is compatible with carbon dioxide in the flue gas of such a system and could be used in a batch process to convert non-volatile epoxides such as glycidol into the corresponding cyclic carbonates. ${ }^{27}$

\section{Catalyst Cost Reduction}

Most aspects of the synthesis of cyclic carbonates using bimetallic aluminium complexes are either unchanged from the current commercial process (e.g. amount of epoxide required), or are self evidently less costly (no need for high pressures and temperatures). The one exception is the cost of the catalyst itself. Therefore a study was undertaken specifically to minimize the cost of production of the catalyst. Analysis of the cost of the chemicals involved in the production of catalyst 1 revealed that significant costs were associated with both the 1,2-diaminocyclohexane and the salicylaldehyde components of the ligand. 1,2-Diaminocyclohexane could be replaced with 1,2-diaminoethane as discussed above, and to minimize the cost associated with the ligand synthesis, the replacement of salicylaldehyde with pentane-2,4-dione was investigated to give complexes 7-9 (Figure 8). ${ }^{28}$ In the presence of tetrabutylammonium bromide as a cocatalyst, complexes 7-9 were all found to be effective catalysts for the synthesis of cyclic carbonates from mono-substituted epoxides at ambient temperature and one bar carbon dioxide pressure and for the synthesis of ethylene carbonate from ethylene oxide at ambient temperature and three bar pressure. The activity of catalysts 7-9 varied according to their solubility in the epoxide used, but catalyst 7 gave excellent results for the production of the commercially important ethylene 
and propylene carbonates and was also the least expensive of the three catalysts to produce. Complex 7 could be prepared for around $78 \%$ of the cost of complex $\mathbf{1}$.

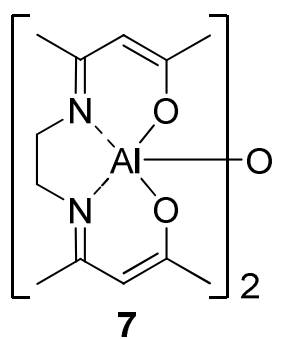

7

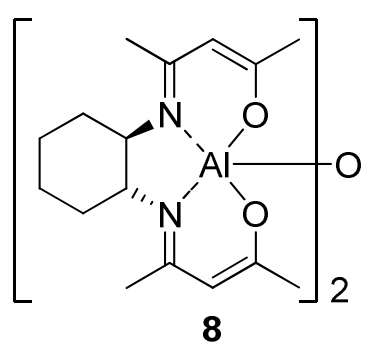

8

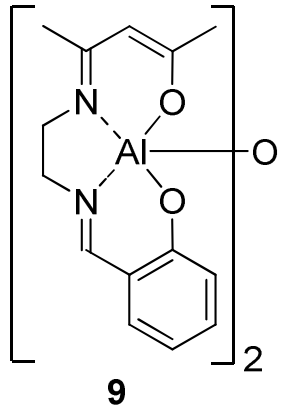

Figure 8. Structures of complexes 7-9.

The cost of the chemicals required for the synthesis of complexes $\mathbf{1}, \mathbf{3 b}, \mathbf{6 a}, \mathbf{6 b}$ and $\mathbf{7}$ was then analyzed. ${ }^{29}$ Figure 9A shows a breakdown of the contribution of the most expensive chemicals for complex $\mathbf{6 a}$ and it is apparent that the cost of producing complex $\mathbf{6 a}$ is dominated by the cost of the aluminium triethoxide which contributes $51 \%$ of the total chemical cost. For the two component catalysts, the contribution of aluminium triethoxide to the overall cost is even higher (69\% for complex 1 and 95\% for complex 7). The next highest contributions are from tetrabutylammonium bromide (used to exchange a chloride to bromide in the synthesis of the one component catalysts and as a cocatalyst with complexes $\mathbf{1}$ and 7) and acetonitrile used as a solvent for the amine quaternizations in the synthesis of one component catalysts $\mathbf{3 b}, \mathbf{6} \mathbf{a}$ and $\mathbf{6 b}$.
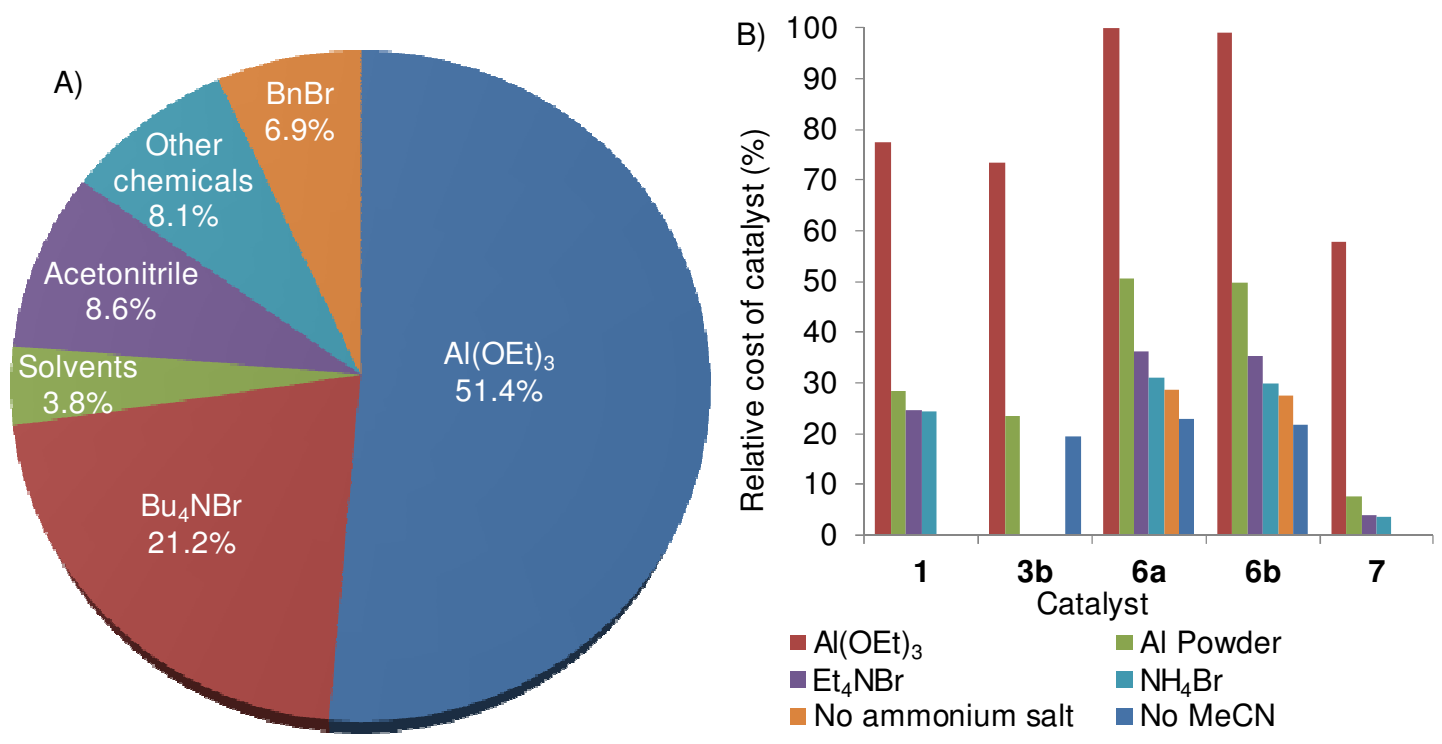

Figure 9. Cost of the chemicals required to synthesize catalysts $\mathbf{1}, \mathbf{3 b}, \mathbf{6 a}, \mathbf{6 b}$ and 7. A) Analysis of the cost of the chemicals required to produce complex 6a. B) Relative cost reductions achieved. 
The use of aluminium triethoxide could be avoided by generating it in situ from aluminium powder and ethanol catalyzed by iodine. Figure 9B shows the magnitude of the resulting cost savings for each of catalysts $\mathbf{1}, \mathbf{3 b}, \mathbf{6 a}, \mathbf{6} \mathbf{b}$ and $\mathbf{7}$. Although it is widely used in cyclic carbonate synthesis, ${ }^{9}$ tetrabutylammonium bromide is significantly more expensive than other ammonium bromides and for the two component catalysts $\mathbf{1}$ and $\mathbf{7}$ we were able to show that it could be replaced with either tetraethylammonium bromide or ammonium bromide resulting in additional cost savings. In the case of silica supported catalysts $6 \mathbf{a}$ and $\mathbf{6 b}$ it was possible to go further and omit the ammonium bromide altogether. The resulting catalyst then had three bromide and one chloride counterions, but displayed identical activity to that of the tetrabromide.

Finally, the acetonitrile used in the preparation of silica supported catalysts $6 \mathbf{a}$ and $\mathbf{6 b}$ could be replaced by propylene carbonate which is an excellent polar aprotic solvent and much cheaper than acetonitrile as well as being more environmentally friendly. The net result of these changes is to reduce the cost of the chemicals needed to produce catalysts $\mathbf{1}, \mathbf{3 b}, \mathbf{6 a}, \mathbf{6 b}$ and $\mathbf{7}$ to between 32 and $7 \%$ of the original costs and allow their production at a cost of $£ 5-30 \mathrm{~mol}^{-1}$ based on bulk scale chemical prices.

\section{Conclusions}

This work has resulted in the development of a class of bimetallic, aluminium based catalysts for the synthesis of cyclic carbonates (including all the commercially important cyclic carbonates) which are active under exceptionally mild reaction conditions. Batch reactions can be carried out at ambient temperature and one bar carbon dioxide pressure whilst continuous flow reactions can be carried out at $100{ }^{\circ} \mathrm{C}$ using catalysts immobilized on amorphous silica. The catalysts have been shown to be compatible with waste carbon dioxide such as that present in unpurified fluegas. The cost of production of the catalysts has been analyzed and routes for their synthesis developed to minimize the cost of their production. The intellectual property associated with this work is protected by three patent families ${ }^{30}$ and a spin-out company (Dymeryx Ltd.) has been established to commercialize the technology. The project provides an excellent illustration of how carbon capture and utilization can provide a sustainable feedstock for use by the global chemicals industry in the $21^{\text {st }}$ century.

\section{Acknowledgements}

The author thanks the EPSRC (grant number EP/K007947/1) for financial support to the $\mathrm{CO} 2 \mathrm{Chem}$ grand challenge network within which the work described in this account was undertaken. 


\section{References}

1. Orr, Jr., F. M. Energy Environ. Sci. 2009, 2, 449.

2. Schrag, D. P. Science 2007, 315, 812.

3. (a) Aresta, M.; Dibenedetto, A. Dalton Trans. 200, 2975. (b) Yu, K. M. K.; Curcic, I.; Gabriel, J.; Tsang, S. C. E. ChemSus. Chem. 2008, 1, 893. (c) Aresta, M. (Ed). Carbon Dioxide as Chemical Feedstock; Wiley-VCH: Weinheim. 2010. pp 1-375. (d) Styring, P.; Armstrong, K. Chem. Today 2011, 29, 28.

4. North, M. Chem. Today 2012, 30, (3 May/June: Monographic supplement: Catalysis applications), 3 .

5. Barzagli, F.; Mani, F.; Peruzzini, M. Green. Chem. 2011, 13, 1267.

6. Aresta, M.; Dibenedetto, A. Catal. Today 2004, 98, 455.

7. Arakawa, H.; Aresta, M.; Armor, J. N.; Barteau, M. A.; Beckman, E. J.; Bell, A. T.; Bercaw, J. E.; Creutz, C.; Dinjus, E.; Dixon, D. A.; Domen, K.; DuBois, D. L.; Eckert, J.; Fujita, E.; Gibson, D. H.; Goddard, W. A.; Goodman, D. W.; Keller, J.; Kubas, G. J.; Kung, H. H.; Lyons, J. E.; Manzer, L. E.; Marks, T. J.; Morokuma, K.; Nicholas, K. M.; Periana, R.; Que, L.; Rostrup-Nielson, J.; Sachtler, W. M. H.; Schmidt, L. D.; Sen, A.; Somorjai, G. A.; Stair, P. C.; Stults, B. R.; Tumas, W. Chem. Rev. 2001, 101, 953.

8. (a) http://www.carbonrecycling.is/. (b) Olah, G. A.; Goeppert, A.; Prakash, G. K. S. J. Org. Chem. 2009, 74, 487.

9. (a) North, M.; Pasquale, R.; Young, C. Green. Chem. 2010, 12, 1514. (b) Decortes, A.; Castilla, A. M.; Kleij, A. W. Angew. Chem. Int. Ed. 2010, 49, 9822.

10. (a) Darensbourg, D. J. Inorg. Chem. 2010, 49, 10765. (b) Kember, M. R.; Buchard, A.; Williams, C. K. Chem. Commun. 2011, 47, 141.

11. Peppel, W. J. Ind. Eng. Chem. 1958, 50, 767.

12. Schäffner, B.; Schäffner, F.; Verevkin, S. P.; Börner, A. Chem. Rev. 2010, 110, 4554.

13. (a) Xu, K. Chem. Rev. 2004, 104, 4303. (b) Etacheri, V.; Marom, R.; Elazari, R.; Salitra, G.; Aurbach, D. Energy Environ. Sci. 2011, 4, 3243.

14. (a) North, M.; Pizzato, F.; Villuendas, P. Chem. Sus. Chem. 2009, 2, 862. (b) North, M.; Villuendas, P. Org. Lett. 2010, 12, 2378. (c) Clegg, W.; Harrington, R. W.; North, M.; Pizzato, F.; Villuendas, P. Tetrahedron: Asymmetry 2010, 21, 1262. (d) Morcillo, M.; North, M.; Villuendas, P. Synthesis 2011, 1918. (e) Beattie, C.; North, M.; Villuendas, P. Molecules 2011, 16, 3420 .

15. Achard, T. R. J.; Clutterbuck, L. A.; North, M. Synlett 2005, 1828.

16. Achard, T. J. A.; Clegg, W.; Harrington, R. W.; North, M. Tetrahedron 2012, 68, 133.

17. Meléndez, J.; North, M.; Pasquale, R. Eur. J. Inorg. Chem. 2007, 3323.

18. Clegg, W.; Harrington, R. W.; North, M.; Pasquale, R. Chem. Eur. J. 2010, 16, 6828.

19. North, M.; Pasquale, R. Angew. Chem. Int. Ed. 2009, 48, 2946.

20. (a) Bu, Z.; Wang, Z.; Yang, L.; Cao, S. Appl. Organometal. Chem. 2010, 24, 813. (b) Wang, Z.; Bu, Z.; Ren, T.; Cao, T.; Yang, L. React. Kinet., Mech. Catal. 2011, 103, 133. (c) Ochoa- 
Gómez, J. R.; Gómez-Jiménez-Aberasturi, O.; Ramírez-López, C. A.; Nieto-Mestre, J.; Maestro-Madurga, B.; Belsué, M. Chem. Eng. J. 2011, 175, 505. (d) Wang, Z.; Bu, Z.; Cao, T.; Ren, T.; Yang, L.; Li, W. Polyhedron 2012, 32, 86.

21. Meléndez, J.; North, M.; Villuendas, P. Chem. Commun. 2009, 2577.

22. North, M.; Villuendas, P.; Young, C. Tetrahedron Lett. 2012, 53, 2736.

23. North, M.; Villuendas, P.; Young, C. Chem. Eur. J. 2009, 15, 11454.

24. North, M.; Villuendas, P. Chem. Cat. Chem. 2012, 4, 789.

25. Meléndez, J.; North, M.; Villuendas, P.; Young, C. Dalton Trans. 2011, 40, 3885.

26. North, M.; Wang, B.; Young, C. Energy Environ. Sci. 2011, 4, 4163.

27. Metcalfe, I. S.; North, M.; Pasquale, R.; Thursfield, A. Energy Environ. Sci. 2010, 3, 212.

28. North, M.; Young, C. Catal. Sci. Technol. 2011, 1, 93.

29. North, M.; Young, C. Chem. Sus. Chem. 2011, 4, 1685.

30. (a) North, M.; WO132474A1, 2008. (b) North, M.; WO109765A1, 2009. (c) North, M.; WO106324A1, 2010.

\section{Author Biography}

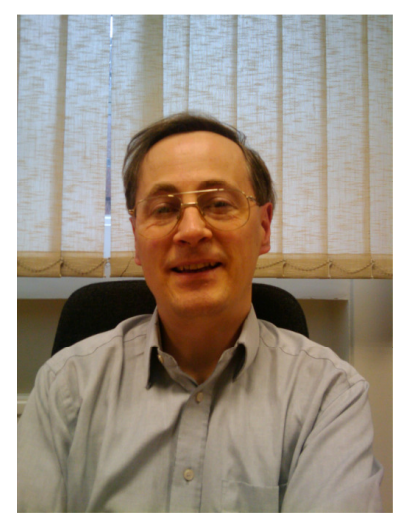

Michael North obtained his BSc. from Durham University and his D.Phil from the University of Oxford. After a postdoctoral position at the University of Nottingham, and academic posts at the University of Wales and the University of London, he was appointed to his current position as Professor of Organic Chemistry and joint director of the University Research Centre in Catalysis and Intensified Processing at the University of Newcastle upon Tyne. He has published over 170 papers and holds six patents. His research interests are centered on the design of new catalysts for asymmetric carbon-carbon bond formation and carbon dioxide chemistry. In 2001 he was awarded the Descartes Prize by the European Commission. 